\title{
Medicine in Old Age
}

\section{Gastrointestinal Problems in the Old-I}

\author{
DENNIS E. HYAMS
}

British Medical fournal, 1974, 1, 107-110

failure, anaemia, uraemia). Anorexia may also arise from their treatment (such as with digitalis, see below).

Gastrointestinal symptoms and diseases increase with ageing, and the commonest lesions are carcinoma (of the stomach or large bowel), peptic ulceration, intestinal obstruction (herniae or diverticular disease of the colon), hiatus hernia, and gallstones. The first three of these caused most of the $20 \%$ of deaths directly due to lesions of the digestive system in McKeown's series of 1,500 necropsies in patients aged 70 or over. ${ }^{1}$ This incidence was second only to diseases of the cardiovascular system as causes of death, and numerically only a little less. Carcinomas of the gastrointestinal system made up nearly half of the total of fatal malignant disease, and half of these were in the large bowel. Disease of the biliary tract has been said to be the commonest pathological finding requiring abdominal surgery in the aged. ${ }^{2}$ In elderly patients with abdominal pain, Ponka et al. found that gallbladder disease was the cause in $27 \cdot 5 \%$. $^{3}$

\section{Functional Changes in the Gut}

Changes have been described in the flow and composition of saliva, gastric juice, bile, and pancreatic juice; in the motility of the stomach and large bowel; in small intestinal absorption; and in large bowel flora. Associated structural changes have also been described. It is doubtful, however, whether these changes contribute significantly to gastrointestinal morbidity in old age. ${ }^{4}$

\section{Common Symptoms}

\section{ANOREXIA}

Appetite may be reduced because of impaired sense of smell and taste, limited activity, dull food, for psychological reasons, or because of various organic disease states. About $10 \%$ of old people are housebound, which increases their vulnerability to many problems. Food may be dull or inadequate when old people find it difficult to obtain - owing to physical disabilities, lack of help, or mental confusion. Depression, isolation, loneliness, apathy, and negativism are all well-known causes of anorexia in the elderly-who are especially vulnerable after bereavement, particularly if living alone. Anorexia is seen in disease of the digestive system, notably carcinoma of the stomach, but is also a frequent symptom in physical disorders elsewhere which have secondary effects on the stomach (heart

Guy's Hospital Department of Geriatric Medicine, New Cross Hospital, London SE14 SER

DENNIS E. HYAMS, M.B., F.R.C.P., Consultant Physician

\section{Management}

Underlying causes must be identified and dealt with. Food should be attractively presented. Attempts to stimulate a poor appetite in old people by drugs, such as cyproheptadine, the oldfashioned nux vomica, or tonics such as Villescon are rarely successful. Alcohol may be more useful. Supplementary feeding (for example, with Complan) may be necessary at times to tide over a difficult period in or after an acute illness; in very weak or ill patients this may have to be given by gastric tube; rarely, parenteral feeding is required. Some very old people reject food or spit it out during feeding. Tube-feeding should be used in such cases only after careful consideration has been given to the medical and ethical aspects of the problem. Even in such cases, however, it is important to avoid dehydration.

Increased appetite in the elderly is usually psychogenic. It is rarely a feature in the elderly thyrotoxic patient.

\section{NAUSEA AND VOMITING}

Nausea and vomiting may be due to diseases of the digestive system itself, or to diseases located primarily elsewhere. It is worth considering this latter group in more detail. Thus heart failure leads to gastric congestion and may produce anorexia, nausea, and vomiting. Cardiac infarction may also be associated with these symptoms. Digitalis intoxication may cause nausea and vomiting, though in the old it is more likely to present as an arrhythmia or a confusional state. This is an important cause of morbidity in the elderly and special care needs to be taken over the use of Lanoxin brand, which is now twice as potent on a weight-for-weight basis as formerly. Plasma digoxin assays are available in some areas and may be helpful if correlated with the clinical state, but in all cases an attempt should be made to relate digoxin dosage to renal function.

Other drugs may produce nausea and vomiting - for example, oestrogens, codeine, dihydrocodeinone, or phenformin. Metabolic disorders are another important cause, especially uraemia, diabetic ketosis, and hypercalcaemia. Labyrinthine disturbance, neurological disorders, and infections are other possible causes.

\section{Management}

The essential principle in management is to treat the underlying cause. For symptomatic treatment, antihistamines and phenothiazines have a time-honoured place as antiemetics, but are rarely without sedative side effects, which may be a nuisance in the elderly patient (who is sometimes unduly sensitive to such effects). Maxolon (metoclopramide) may be of use if this is the case. 


\section{DYSPHAGIA}

This is a common and important complaint in the old. It must never be regarded as functional unless the fullest possible investigation has been carried out-and even then the patient must be reviewed frequently and carefully. The difficulty in swallowing may affect solids but not liquids, and some types of solid food are easier to cope with than others. Food may stick at a consistent level, and then move on or be regurgitated, but the elderly patient's description of the level may be inaccurate. At times the initiation of the swallowing reflex seems impaired, and food is chewed for long periods but finally rejected. The risk of "spillover" into the trachea is common in patients with neurologicallycaused dysphagia, and they may be afraid to swallow. The alarm which dysphagia causes to an elderly patient must always be remembered: the fear of cancer will be there.

Causes of Dysphagia

\begin{tabular}{|c|c|c|}
\hline Type & Position & Causes \\
\hline \multirow[t]{2}{*}{ Local } & $\begin{array}{l}\text { Mouth } \\
\text { Larynx } \\
\text { Pharynx }\end{array}$ & $\begin{array}{l}\text { Tongue lesions, especially carcinoma } \\
\text { Carcinoma } \\
\text { Diverticulum (usually traction) } \\
\text { Postcricoid web (Paterson-Kelly syndrome) or } \\
\text { carcinoma } \\
\text { Infections, abscess }\end{array}$ \\
\hline & $\begin{array}{l}\text { Extrinsi: } \\
\text { Stomach }\end{array}$ & $\begin{array}{l}\text { Carcinoma (especially mid-level) } \\
\text { Stricture (hitaus hernia) } \\
\text { Spasm ("corkscrew" oesophagus) } \\
\text { Achalasia } \\
\text { Diverticula (traction) } \\
\text { Pressure (unfolded aorta-“"dysphagia lusoria") } \\
\text { Foreign body } \\
\text { Carcinoma of cardia } \\
\text { Hiatus hernia (rolling-paraoesophageal—or } \\
\text { sliding with ulceration or stricture) }\end{array}$ \\
\hline Remote & Neurological & $\begin{array}{l}\text { Disorders of brain-stem (pseudobulbar palsy, } \\
\text { stroke, posterior inferior cerebellar artery } \\
\text { syndrome) }\end{array}$ \\
\hline
\end{tabular}

\section{Management}

The primary cause must be dealt with as effectively as possible. The ethical problems of prolonged tube-feeding have been mentioned briefly above. The situation is influenced, on the one hand, by the likely prognosis and quality of life, and, on the other, by the likely mode of death-an aspect too often neglected by doctors. Neither choking nor dehydration permits death with dignity. Where a nasogastric tube cannot be passed, a Mousseau-Barbin tube may be inserted at oesophagoscopy, to maintain a lumen in the oesophagus. Gastrostomy is not justified in the elderly-and perhaps not at any age, as it produces so much distress itself.

\section{CHANGE IN BOWEL HABIT}

This must always be taken seriously.

\section{Diarrhoea}

Acute diarrhoea may occur for the usual reasons (food poisoning, dietary indiscretion), but inquiry should also be made for possible abuse of purgatives. Spurious diarrhoea, due to faecal impaction (see below), is common in old people.

Chronic diarrhoea raises the suspicion of carcinoma of the colon or rectum, but may also be due to other diseases of the gastrointestinal tract, especially diverticular disease of the colon, ulcerative coloprostitis, or commonly faecal impaction. Diarrhoea may be due to steatorrhoea, possibly after an earlier partial gastrectomy, or due to abuse of purgatives.

Systemic disorders associated with diarrhoea include uraemia, diabetes, thyrotoxicosis, and liver disease. Psychogenic causes may occur in old age, as in younger persons.

Old people with diarrhoea may develop faecal incontinence due to the urgency of the desire to defaecate, the fluid or semiformed stool, and possibly impaired mobility, a too-distant lavatory, and occasionally laxity or weakness of the anal sphincter.

\section{Faecal Incontinence}

The causes of faecal incontinence may be local or distant. Of local causes, diarrhoea is the commonest, but rectal prolapse or prolapsed haemorrhoids may be present. Rarely is faecal incontinence due to simple weakness or laxity of the sphincter. Distant causes include brain damage or dementia, leading to lack of cortical inhibition, but this cause is less common than a local cause-in contrast to urinary incontinence, where the converse applies. Spinal cord lesions are rare causes of faecal incontinence in the old.

Faecal incontinence can be the final straw which breaks down attempts to nurse an old person at home; by earning for him the erroneous label of "senile" or "mental" it may lead to misplacement of the patient in a mental hospital.

\section{Constipation}

Many old people are constipated, and even more are convinced that they are, since preoccupation with the bowels is common in old age. The importance of constipation is that it may lead to severe complications. Constipation is best thought of not in terms of transit-time through the gut, which is slowed in old age $^{56}$ without necessarily causing symptoms, but rather the type of faeces produced-that is, hard and dry.

About half the elderly people studied in various surveys take laxatives, often unnecessarily.

Causes.-Primary causes are slow transit-time (especially in bedfast patients); incomplete emptying (poor muscle tone, unsatisfactory toilet arrangements, laziness, mental confusion, or dementia); diminished awareness of a loaded or overloaded rectum; neglect of the call to defaecate; low-bulk diet (ignorance, cost, poor dentition); and inadequate fluid (sometimes due to fear of urinary difficulties).

Secondary causes of constipation may be gastrointestinal or otherwise. Diverticular disease of the colon and carcinoma of the colon or rectum must be considered. Anorectal lesions such as fissures, haemorrhoids, or pectenosis ${ }^{7}$ may contribute.

Other important causes include drugs (codeine and dihydrocodeine, morphine, iron, aluminium compounds, calcium salts, and anticholinergics), hypothyroidism, and mental disorders.

Combined causes may also be present: as usual in the elderly, there may be several factors operating to produce the disability:

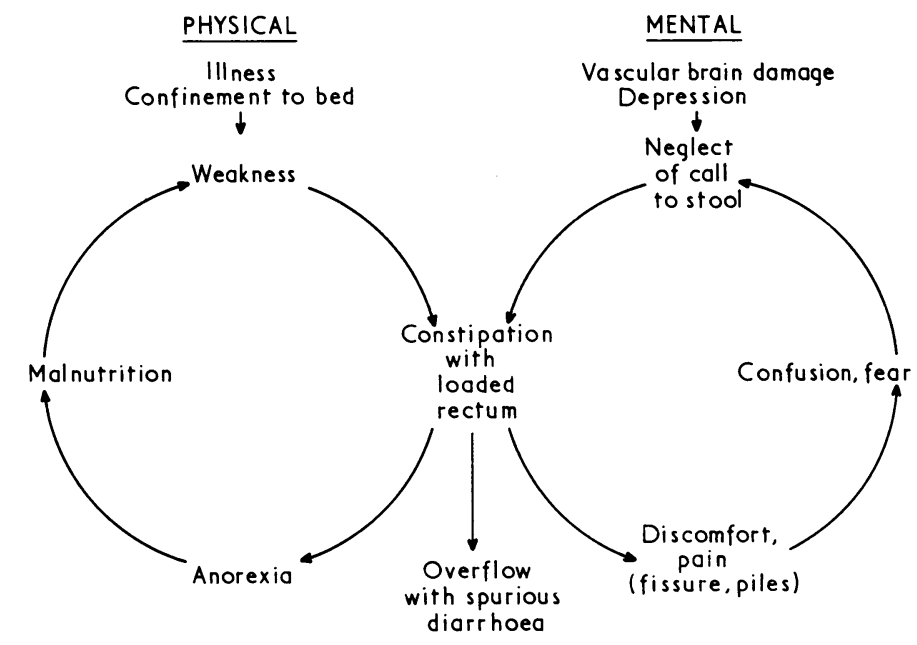

Vicious Circles of Constipation in the Elderly ${ }^{8}$ 
Wilkins has illustrated the vicious circles which may develop (fig. 1). ${ }^{8}$

Complications.-The main complication is faecal impaction. Faecal retention plus absorption of fluid in the large bowel leads to hardening of faeces, which are packed together by peristaltic waves and lubricated by excess secretion of mucus. The impaction over-distends the rectum; but very occasionally it may occur higher in the colon while the rectum remains empty. Sometimesimpaction of a great mass of soft faeces occurs in weak patients.

Faecal impaction may lead to:

(1) Faecal incontinence. Impacted faeces act as a ball-valve and more liquid stool at a higher level leaks around the faecal mass. Stretching of the anal ring is corrected only when the rectum is cleared; until then the "spurious diarrhoea" will continue.

(2) Intestinal obstruction. This may have a high mortality or may lead to unnecessary surgical intervention.

(3) Mental disturbances. Restlessness and confusion may be due to faecal impaction. This might be termed the "recto-cephalic reflex." It is worth remembering this simple mechanism when dealing with disturbed or restless old people; it could save many an unwarranted admission to hospital. Sedation of the patient without a preliminary rectal examination is poor medical practice.

(4) Retention of urine. This may be associated with overflow urinary incontinence, possibly due to pressure of the distended rectum on the bladder neck.

(5) Rectal bleeding. This may occur owing to the ulceration of the mucosa; the presence of a neoplasm must be excluded.

Other gastrointestinal effects may occur with constipationfor example, megacolon, with an atonic colon, or volvulus of the colon, producing intestinal obstruction. Gross gaseous distension of the bowel may produce angina pectoris and electrocardiographic changes.

Another important complication of constipation results from straining. Adverse effects of straining have been clearly demonstrated on the coronary, cerebral, and peripheral arterial circulation. In the eiderly with cerebrovascular disease transient ischaemic attacks may occur; in those with impaired baroreceptor reflexes and a tendency to postural hypotension, the Valsalva manoeuvre is produced by straining at stool and the patient may develop syncope. This mechanism may account for the not infrequent history of finding the patient on the lavatory floor.

Symptoms of hiatus hernia may be aggravated by the rise in intra-abdominal pressure on straining.

\section{Management}

Proper management of diarrhoea is impossible without a rectal examination. The underlying cause must be treated as far as possible. For symptomatic treatment, in acute cases, food should be withheld for up to 24 hours, but fluids must be given liberally to avoid dehydration. Kaolin or activated attapulgite are available in various preparations, sometimes combined with opiates or antibiotics. They are useful for relieving symptoms but should only be used when the cause of the diarrhoea has been diagnosed with reasonable certainty. Stool cultures should be taken before using antibiotics; rectal swabs are far less reliable. In the elderly, care should be taken about the use of these medicines; it is bad clinical practice to give kaolin mixtures to patients with diarrhoea which is spurious and secondary to faecal impaction! Injudicious use of opiates may mask the diagnosis of important abdominal pathology. Lomotil is useful to reduce transit time in the intestine. Codeine phosphate tablets may also be used but may encourage vomiting. Hydrophilic bulking agents such as Metamucil, Isogel, or Celevac-while mainly of use in the treatment of constipation-may also be of value in diarrhoea if taken with jam rather than water. They then absorb water from the stool and improve its consistence. This is of particular value in helping to regulate the functioning of a colostomy.
Similar considerations apply in the management of chronic diarrhoea. Accurate diagnosis is essential. Particular attention should be paid to fluid and electrolyte (especially potassium) balance.

In the management of constipation the underlying causes must also be treated on their merits. In general management, reassurance and explanation will help if habits need re-training: physical activity, fluid intake, and the amount of bulk in the diet require attention. Some old people are helped by a glass of hot water first thing in the morning as a regular habit. Toilet arrangements may require revision. While low lavatory seats are difficult for the elderly to cope with, some degree of squatting aids defaecation; excessive zeal in raising the level of the seat may actually hinder efficient defaecation. (Nevertheless, polyethylene seat raises are valuable in many arthritic old people.)

Laxatives.-There are three main types of laxatives. Firstly, the bulking agents. Many people (old and young) live on diets low in fibre content, which produce small, hard, and infrequent stools. Bulking agents are bland and absorb water, increasing volume of the stool. This is the most physiological way of dealing with constipation and diverticular disease of the colon.

Unprocessed bran is an ideal additive to the diet in such cases-and in their prevention. It may be sprinkled on cereals or other foodstuffs. Probably most old people would benefit from its regular consumption, but its high phytic acid content might impair calcium absorption in subjects with latent or overt vitamin D deficiency-and there is increasing evidence that this might be commoner in the elderly than previously thought. Other hydrophilic agents in this category include semisynthetic cellulose ethers (Celevac, Cologel), and mucilaginous substances (Metamucil, Isogel, and Normacol). These agents should be taken with abundant liquids to avoid the potential hazard of intestinal obstruction from bolus formation, especially when intestinal motility is reduced or if there is intestinal disease.

The second type of laxatives are the stimulant ones. The anthracene laxatives are best represented by senna, available in standardized form as Senokot. Its main effect is on the transverse and distal colon, so that stools are likely to be formed, and fluid and electrolyte disturbances are unlikely.

Bisacodyl (Dulcolax) is a contact laxative and more likely than Senokot to produce liquid stools and (in the elderly) the risk of faecal incontinence; it is also more likely to cause severe griping. Phenolphthalein has no place in modern therapeutics.

The other stimulant laxatives, including irritants like colocynth, jalap, podophyllum, aloes (all contained in vegetable laxative tablets), and croton-oil, have no place in modern management of constipation at any age.

Thirdly, the osmotic laxatives, or "salts"-soluble sulphates, phosphates or tartrates of sodium, potassium or magnesiumact by the osmotic effects of their ions retaining large volumes of fluid throughout the bowel. The disturbance to normal gut physiology is considerable, the stools are loose, and fluid and electrolyte disturbance likely. These agents are best kept for special indications only (for example, food-poisoning). Lactulose acts only when acted on by colonic bacteria, but may have undesirable effects on the latter, and may cause gaseous distension. It may be useful to clear the colon in hepatic failure, and where there is colonic retention of barium after a barium meal."

Stool Softeners.-Dioctylsodium sulphosuccinate (DOS) and poloxalkols are surface-active "wetting" agents, which are said to penetrate hard stools and to help soften them. The formation of hard stools is said to be prevented during the administration of these drugs. They are popular in geriatric practice, but it is only fair to point out that the possible effects (especially the longterm ones) of the consumption of detergents are not yet fully known. In animals they have been shown to cause changes in gut physiology.

Combinations of these agents with stimulant laxatives (for example, Dulcodos, bisacodyl plus DOS; Dorbanex, danthron plus poloxalkols) have been found useful in geriatric patients, but, again, some caution is required, since other combinations of 
this type have had adverse effects in large doses or in chronic usage.

Liquid paraffin, once thought harmless, has now earned itself a bad name. It may impair absorption of fat-soluble vitamins, leak from the anus, be aspirated into the lungs to cause lipoid pneumonia, and be absorbed (especially when given in emulsion form) and be deposited in body tissues. These risks are greater in the elderly, and its use should be avoided-at least as a regular habit.

Rectal Evacuation.-Suppositories of glycerine or bisacodyl are sometimes helpful. The latter may cause local discomfort. Enemas should be small-volume solutions: oil for softening and saline for evacuation. Disposable hypertonic saline enemas are convenient, gentle, and reasonably effective. Soap should never be used in enemas.

Manual Removal of Faeces.-This may be required in the initial treatment of faecal impaction: oral laxatives cannot be expected to clear the bowel when the lower end is plugged so effectively with accumulated faeces. Suppositories and enemas may also fail in this situation, although a small-volume enema should be tried as the first step, and this may be repeated daily, its efficacy being judged by repeated digital examinations. With soft faecal impaction bisacodyl suppositories may also be successful: one should be used high up in the rectum and repeated once if there has been no result after two hours.
Large volume washouts with saline may be needed to clear the lower bowel if impaction is high above the rectum.

In the management of faecal incontinence, since most cases are due to spurious diarrhoea associated with faecal impaction, treatment of the latter will deal with the incontinence. For the neurogenic type of faecal incontinence, a regimen of Mist. kaolin et morph., $15 \mathrm{ml}$ every morning, alternating with Senokot 1-2 tablets every night has been advocated by Jarrett and Exton-Smith. ${ }^{10}$ In such cases it is essential to exclude the presence of faecal impaction.

\section{References}

1 McKeown, F., Pathology of the Aged. Butterworth, London, 1965.

2 Strohl, E. L., Diffenbaugh, W. G., and Anderson, R. E., Geriatrics, 1964, $19,275$.

3 Ponka, J. L., Welborn, J. K., and Brush, B. E., Fournal of the American Geriatrics Society, 1963, 11, 993.

Hyams, D. E., Modern Geriatrics, 1973, 3, 352.

Hyams, D. E., Gerontologia Clinica, 1964, 6, 193.

- Brocklehurst, J. C., and Kahn, M. Y., Gerontologia Clinica, 1969, 11, 293.

7 Exton-Smith, A. N., in Management of Constipation, p. 156. Avery-Jones, F. and Godding, E. W., Blackwell Scientific Publications, Oxford, 1972. 8 Wilkins, E. G., Postgraduate Medical fournal, 1968, 44, 728.

- Prout, B. J., Datta, S. B., and Wilson, T. S., British Medical Fournal $1972,4,530$.

10 Jarrett, A. S., and Exton-Smith, A. N., Lancet, 1960, 1, 925.

\title{
Today's Treatment
}

\section{Diseases of the Skin}

\section{Drug Ill Effects on the Skin}

\author{
P. W. M. COPEMAN
}

British Medical fournal, 1974, 1, 110-113

No systemically administered medication escapes the stigma of causing a rash. Drugs have actions, wanted and unwanted, and the commonest complication of drug treatment is a rash. It may be associated with a systemic disorder (perhaps a third of patients have some sort of kidney dysfunction), but practically always this is minor.

The mechanisms of most drug rashes are mysterious. Allergy has rarely been proved in the individual case. Most of the many diagnostic tests designed so far rely on an immunological system and therefore will not be indicators of other pathological processes. If a simple infallible, rapid, and humane diagnostic test could be devised to implicate the drug, it would transmute the subject of drug eruptions from mythology to science. The drug, so often a scapegoat, might then be absolved when, say, an intercurrent minor virus infection should have been blamed.

\section{Westminster Hospital, London} P. W. M. COPEMAN, M.D., M.R.C.P., Consultant Physician for Disease of
the Skin

\section{Diagnostic Considerations}

The diagnosis is necessarily based on supposition not science. Two main aspects are usually considered: firstly, the timing of the administration of the drug related to the onset of the rash; and secondly the odds. This is a type of league table which balances the drugs that are top suspects (table I) against the form of the eruption. Table II classifies other types of eruption, whose pathogenesis is almost entirely unknown.

The reported frequency of drug rashes depends upon the vigilance of the observers, the prescribing habits of the doctors, the self-medication urges of the patients themselves, and (of increasing importance), the unknowing exposure to drugs, as, for example, quinine in beverages such as Bitter Lemon.

The apparent incidence of rashes may be misleading. Plainly the antibiotics labelled "high risk" are prescribed for more patients than are the hydantoins, which I have listed under "common offenders" - and yet hydantoin may be the more active culprit causing a great diversity of rashes in a higher proportion of patients for whom it is prescribed.

The properties of the drug itself, its impurities, the excipients, and its metabolites will need to be considered. The antigenic determinants may be relevant and may number at least three in sulphonamides and over a dozen in the penicillins.

The type of rash is important diagnostically. An acute erup- 